\title{
Recency effects in delayed recall of mouthed stimuli
}

\author{
ROBERT L. GREENE \\ Case Western Reserve University, Cleveland, Ohio \\ and \\ ROBERT G. CROWDER \\ Yale University, New Haven, Connecticut
}

\begin{abstract}
Auditory presentation leads to greater recency effects in recall than does visual presentation. This phenomenon (the modality effect) is found in both free and serial recall and in both immediate and delayed recall. Silent mouthing of visually presented stimuli also leads to enhanced recency effects in immediate serial recall. Two experiments reported here extend the generality of the mouthing effect by demonstrating that enhanced recency effects of mouthed stimuli occur in delayed serial and free recall. These results are inconsistent with theories that attribute the modality effect to a purely auditory sensory memory.
\end{abstract}

Recency effects in recall tend to be much larger following auditory than visual presentation (Corballis, 1966). This advantage at the end of a list for items that are heard rather than seen is known as the modality effect. A similar effect is found when all items are presented visually, and subjects are required to read the items either aloud or silently: recall of terminal items is greatly enhanced for lists that are read aloud (Conrad \& Hull, 1968; Crowder, 1970; Murray, 1966).

One of the most striking properties of the modality effect is its wide generality. Modality effects can be demonstrated in either immediate serial recall (e.g., Conrad \& Hull, 1968; Corballis, 1966; Murray, 1966) or immediate free recall (e.g., Craik, 1969; Murdock \& Walker, 1969). They are also found in delayed serial recall (Routh \& Mayes, 1974; O. C. Watkins \& M. J. Watkins, 1980, Experiment 6) and delayed free recall (e.g., D. E. Broadbent, Vines, \& M. H. P. Broadbent, 1978; Engle \& Roberts, 1982; Gathercole, Gregg, \& Gardiner, 1983; M. J. Watkins, O. C. Watkins, Craik, \& Mazuryk, 1973) when the retention interval is filled with a silent distractor task. Modality effects are even present in the continuous-distractor paradigm, a form of delayed free recall in which a vocalized distractor task occurs after every item (or pair of items) on the list (Gardiner \& Gregg, 1979; Glenberg, 1984; Greene, 1985).

Many different explanations have been offered for the modality effect. The theory that has received the greatest attention suggests that the modality effect, in at least some circumstances, reflects the operation of auditory sensory

Financial support for this research was provided by NSF Grant No. BNS 82-19661. Requests for reprints should be sent to R. L. Greene, Department of Psychology, Case Western Reserve University, Cleveland, $\mathrm{OH} 44106$ memory, also called precategorical acoustic storage (PAS; Crowder \& Morton, 1969). According to this account, auditory sensory information remains accessible for an extended period of time after the presentation of a stimulus. This auditory information can then be used in recall. If an irrelevant sound (a stimulus suffix) occurs after the last item on a list, the auditory recency effect is greatly reduced (Crowder, 1967; Dallett, 1965). According to the PAS theory, the stimulus suffix interferes with auditory information about the last item in echoic memory.

Recent findings have challenged the PAS account of the modality effect. Particularly important has been evidence for enhanced recency effects in recall of nonauditory information. Silent articulatory gestures lead to patterns of recall formerly believed to occur only with auditory presentation. Enhanced recency effects result from recall of lists that are lip-read by the subjects (Campbell \& Dodd, 1980; Greene \& Crowder, 1984, Experiment 3; see also Spoehr \& Corin, 1978). A similar pattern is found when subjects silently articulate (or "'mouth") visually presented items (Greene \& Crowder, 1984, Experiments 1 and 2; Nairne \& Walters, 1983). Just as reading an item aloud (active vocalization) leads to patterns of recall similar to hearing someone else read the item (passive vocalization), silent mouthing (active articulation) and watching someone else mouth items (passive articulation) result in similar patterns of recall.

The enhanced recency effects found with lipread or mouthed stimuli often have been seen as inconsistent with the PAS account of the modality effect (e.g., Coltheart, 1984; Crowder, 1983; Gardiner, 1983; Greene \& Crowder, 1984). However, as Greenberg and Engle (1983) argued, such a conclusion may be premature. Greenberg and Engle pointed out that the lipreading and mouthing effects may result from processes different from those that 
result in the standard modality effect. In other words, the lipreading and mouthing data could actually be irrelevant to interpretations of the standard modality effect. One could then keep an echoic-memory account of the standard modality effect while seeking a different explanation for the enhanced recency effects found in lipreading and mouthing.

Thus, establishing whether the results found with silent articulatory gestures are related to the modality effect is important. One can do this by determining whether the two sets of results behave similarly under a variety of experimental manipulations. One relevant finding has already been made by Greene and Crowder (1984, Experiment 1), who demonstrated that the mouthing recency effect, like the modality effect found with auditory presentation, was reduced or eliminated for lists of acoustically similar items. However, as Greene and Crowder noted, this single finding is far from conclusive. Similarity might affect recall of mouthed items and auditory items in the same way but for different reasons. For example, since acoustic similarity is necessarily related to articulatory similarity, acoustic similarity could affect the magnitude of the standard modality effect, but articulatory similarity could determine the level of mouthing recency.

The experiments reported here were intended to collect additional evidence on the question of whether auditory recency and mouthing recency reflect similar processes. The goal was to find out whether the mouthing effect is found in the same variety of situations as is the standard modality effect. Previous examinations of the mouthing effect were restricted to immediate serial recall. The present experiments examined the effects of mouthing in delayed serial recall and in the continuous-distractor paradigm of delayed free recall. The presence of enhanced recency effects for mouthed stimuli in these paradigms would be consistent with the assumption that mouthing and auditory recency effects reflect similar processes.

\section{EXPERIMENT 1}

The standard modality effect has been found in delayed serial recall (Routh \& Mayes, 1974; O. C. Watkins \& M. J. Watkins, 1980). Experiment 1 was intended to demonstrate a mouthing effect in delayed serial recall. All lists were presented visually. Subjects were required to read the items aloud or silently or to mouth them silently. After the final item, subjects performed an arithmetic task for $40 \mathrm{sec}$ before attempting to recall the items in order.

\section{Method}

Subjects. Thirty-six adults participated in this experiment. They were recruited by signs distributed around campus and were paid $\$ 4$.

Materials. Forty-two lists, each consisting of six one-syllable four-letter nouns, were constructed. Each word occurred once in the experiment. All lists were shown in the same order to all subjects. The order of the items on each list was counterbalanced across subjects so that each item occurred equally often at each of the six positions for all conditions. All items were displayed on a computer terminal controlled by a NorthStar Horizon computer system.
Procedure. All subjects were tested individually while seated in front of the terminal. They saw lists of six words, shown in the middle of the screen at a rate of one item every $2 \mathrm{sec}$. After the sixth word, two-addend addition equations (e.g., 1+2=3) appeared. Subjects were required to press one key on the terminal keyboard if the equation was true and a different key if the equation was false. Equations were shown at a $2-\mathrm{sec}$ rate. Subjects had to respond to 20 equations after each list, making the filled retention interval $40 \mathrm{sec}$ long. After this period was over, subjects had to write down the list items in order on a piece of paper. They were required to start at the first space and fill in the six spaces consecutively, drawing a line through any space they left blank. An experimenter sat facing the subject to ensure compliance with the instructions.

The main independent variable involved the way in which subjects read the list items that were shown on the terminal screen. Equal numbers of subjects were asked to read each item aloud as it was shown, to read each item silently, or to mouth each item vigorously. Those subjects in the mouthing condition were told to avoid making any sound as they articulated the words.

In all, each subject saw 42 lists. The first 2 lists were considered practice and were not included in the analyses.

\section{Results and Discussion}

The results from Experiment 1 are shown in Figure 1. There are two ways to score data from a serial-recall experiment. One can count an item as being correct if it was recalled at any position (item criterion), or one can require that an item be assigned to the correct position (position criterion). As can be seen from the figure, both methods of scoring led to essentially the same conclusions. There was little difference between the aloud and silent conditions at the beginning of a list. However, there was a marked advantage for the aloud condition further in the list; this advantage is greatest at the last position. This is the standard modality effect. Mouthing hurt performance on the first couple of items, possibly because it is a relatively novel task and interferes with rehearsal. However, the mouthed condition exhibited a larger recency effect than did the silent condition. This replicates the general pattern found in immediate serial recall by Greene and Crowder (1984, Experiment 1).

An analysis of variance on the absolute number of items recalled, scored according to the item criterion, resulted in a significant effect of serial position $[F(5,165)=26.32$,

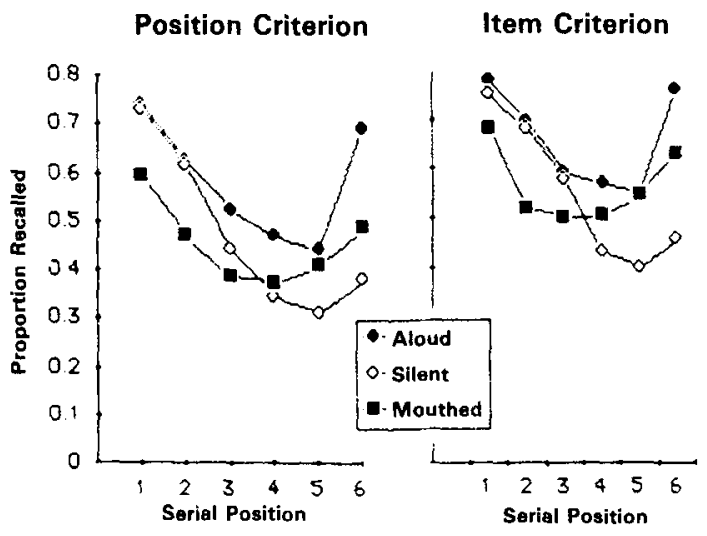

Figure 1. Proportion of items recalled in Experiment 1, scored according to the position criterion (if an item is recalled in the correct position) or the item criterion (if an item is recalled at all). 
$M S e=17.69]$ and a significant interaction between condition (aloud, silent, or mouthed) and position $[F(10,165)$ $=4.44, M S e=17.69$ ]. When the position criterion was used to score the data, identical conclusions were reached. The main effect of position $[F(5,165)=43.08, M S e=$ 18.77] and the interaction between condition and position $[F(10,165)=4.37, M S \mathrm{e}=18.77]$ were again significant. The main effect of condition was not significant using either criterion for scoring.

The focus of this research was not on main effects, but rather on the interaction between condition and serial position and particularly on the influence of condition on the magnitude of the recency effect. For purposes of statistical analysis, the recency effect was defined as the difference between the recall of the last item and the average level of recall of the previous items. This measure has been used in several previous studies of modality and stimulus-suffix effects (e.g., Greene, 1985; Greene \& Crowder, 1984; M. J. Watkins \& Todres, 1980; O. C. Watkins \& M. J. Watkins, 1982). Using this measure of recency as the dependent variable, when the data were scored using the item criterion, there was a significant overall effect of condition $[F(2,33)=4.84, M S e=$ 41.61]. The crucial question is whether the mouthing subjects exhibited significantly more recency than did the silent subjects. This comparison of means was indeed significant $[F(1,22)=4.42, M S e=45.62]$. Additional comparisons of means showed that there was no difference between the mouthing and aloud groups $[F(1,22)=$ $0.71, M S e=55.00]$ and that there was significantly more recency in the aloud than in the silent groups $[F(1,22)=$ 15.93, $M S e=24.21]$. This latter finding is simply a replication of the basic modality effect.

Identical conclusions are reached by scoring the data using the position criterion. There was a significant overall effect of group on recency $[F(2,33)=4.56, M S e=$ 43.90]. Once again, the crucial comparison between the mouthing and silent groups was significant $[F(1,22)=$ $4.33, M S e=44.60$ ], as was the comparison of the aloud and silent groups $[F(1,22)=13.70, M S \mathrm{e}=29.20]$. There was again no significant difference between the aloud and mouthing groups $[F(1,22)=1.55, M S e=57.89]$.

We consider this sort of recency measure to be useful when trying to compare recency effects between conditions that differ greatly in their overall levels of recall. However, there may be questions as to whether our conclusions, and particularly our finding of a significant mouthing enhancement of recency, result from the particular measure we used. To address this possibility, we also carried out analyses on the raw number of items recalled from the last position. The crucial comparison between the mouthing and silent group was significant using either the item criterion $[F(1,22)=4.87, M S \mathrm{Se}=$ $44.38]$ or the position criterion $[F(1,22)=4.50, M S e=$ 36.41]. Mouthing led to enhanced absolute levels of recall of terminal items, as well as enhanced relative recency. For completeness, we note that the overall effect of condition, the difference between the aloud and mouthing groups, and the difference between the aloud and silent groups were also significant in this analysis using either the item or position criteria. ${ }^{1}$

Experiment 1 demonstrated a mouthing modality effect in delayed serial recall. This experiment extended previous research on mouthing recency effects in several other ways as well. This was the first experiment to demonstrate a mouthing effect in recall of words; previous mouthing experiments used letters or numbers. Also, in Experiment 1, each word occurred only once in the entire experiment. Previous experiments in this area used orderings of constrained sets of items as lists, with each item occurring on many different lists during a session. Finally, the list length was shorter here than in previous experiments. Although there was no specific reason to expect any of these factors to be crucial, it is comforting to know that the mouthing effect is robust against manipulations of these factors. This is one more way in which the mouthing effect resembles the standard modality effect.

\section{EXPERIMENT 2}

The most surprising situation in which the standard modality effect occurs (at least to adherents of an echoicmemory account of the effect) is in the continuousdistractor paradigm. In this paradigm, first developed by Bjork and Whitten (1974), each item (or pair of items) is preceded by a period of distractor activity. The last item is followed by another period of distractor activity. Large modality effects can be found in free recall using this paradigm, even when the distractor activity involves vocalization that would be sufficient to eliminate the modality effect if it had occurred only after the last item (Gardiner \& Gregg, 1979; Glenberg, 1984; Greene, 1985). This is very hard to reconcile with an echoicmemory account of the modality effect in free recall.

Experiment 2 determined whether mouthing would lead to enhanced recency effects in the continuous-distractor paradigm. List items were read aloud, read silently, or silently mouthed by the subjects. Each item was preceded and followed by a 10-sec interval in which the subject had to count backward. This counting task was performed either aloud or with mouthing. After the 10-sec interval following the last item, subjects were asked for free recall.

\section{Method}

Subjects. Seventy-two undergraduates participated in this experiment to fulfill a course requirement. All subjects were tested individually.

Materials. Twenty-four lists, each consisting of six four-letter one-syllable nouns, were constructed. Each word occurred only once in the experiment. The order of presentation of the lists was fixed. Items within a list were counterbalanced across subjects so that all items occurred equally often at each position in each condition.

Procedure. There were two manipulations of interest in this experiment. The first was the manner of reading the list items (reading silently, reading aloud, or silently mouthing). This was a withinsubject variable, applied in counterbalanced order. The second manipulation involved the distractor activity that preceded and fol- 
lowed each of the list items. This activity involved either reading aloud or silent mouthing. This was a between-subjects variable.

All stimuli were shown on a computer terminal controlled by a NorthStar Horizon computer system. At the beginning of a list, a three-digit number, randomly chosen by the computer, appeared for $.5 \mathrm{sec}$ in the middle of the terminal screen. Half of the subjects were required to read this number aloud as soon as they saw it. The remaining subjects had to mouth the number silently. The number then went off the screen, and a single asterisk appeared and started flashing at a rate of twice per second. Subjects had to count backward by threes at this pace. This involved either saying the numbers aloud or mouthing them. After $10 \mathrm{sec}$ had passed, the asterisk went off the screen, and a word appeared on the screen for $1 \mathrm{sec}$. One second after the word went off the screen, another number appeared, and the subjects were to begin counting backward again. This continued until the subject had seen six words and gone through seven periods of counting backward. Then the subject was asked for free recall of the words. When subjects felt that they could not recall any more items, they pressed a key on the terminal to begin the next list.

In all, each subject went through 24 lists. On 8 of the lists, the subject was required to read each word aloud as it was shown. On another 8 lists, the words had to be read silently. On the remaining lists, the subject silently mouthed the items. The 8 lists in each condition occurred successively; in other words, manner of reading the list items was blocked. An experimenter sat facing the subject to monitor compliance with the instructions. The first list in each condition was considered practice and was not scored.

\section{Results and Discussion}

The results are shown in Figure 2. In a free-recall experiment such as this, position scoring is not appropriate, so all scoring is done using the item criterion. The serial-position curves look similar for both distractor conditions. In both panels, the items read aloud exhibited greater recency than did items read silently. This is the long-term modality effect (Gardiner \& Gregg, 1979). The mouthing condition also led to greater recency than did the silent condition. Therefore, the results from the continuous-distractor paradigm qualitatively resemble those found in immediate recall.

An overall analysis on the absolute number of items recalled found significant main effects of manner of reading the stimuli (reading aloud, reading silently, or silently mouthing) $[F(2,140)=35.70, M S e=1.64]$ and of position $[F(5,350)=39.92, M S e=2.40]$ and a significant

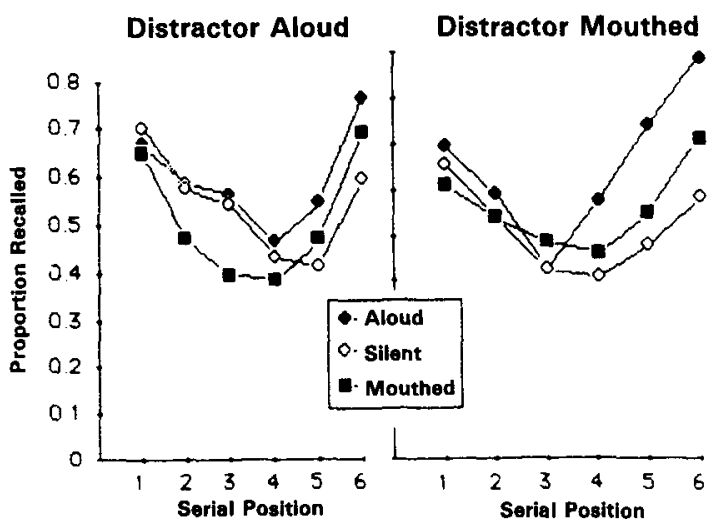

Figure 2. Proportion of items recalled in Experiment 2. interaction between these two variables $[F(10,700)=$ $4.77, M S e=1.57]$. No other main effects or interactions were significant.

An analysis of variance was performed in which the magnitude of the recency effect was again defined as the difference in level of recall between the last item and the average of the other positions. The nature of the distractor activity (aloud or mouthed) had no effect on the magnitude of recency $[F(1,70)=0.01, M S e=3.67]$ and also did not interact with any other comparison. This variable, therefore, will not be discussed further. However, the manner of reading the stimuli (aloud, silent, or mouthed) did significantly affect recency $[F(2,140)=7.93, M S e$ $=2.12]$.

The crucial comparison in this experiment is between the mouthing and silent conditions. Once again, there was a significant difference $[F(1,70)=5.15, M S e=2.24]$, with mouthing leading to an enhanced recency effect. Additional comparisons of means showed the expected advantage in recency for the aloud over the silent condition $[F(1,70)=15.63, M S e=2.13]$ and no significant difference between the aloud and mouthing conditions $[F(1,70)$ $=2.82, M S \mathrm{e}=2.00]$

To eliminate the possibility that our results depend on our choice of dependent measure, we carried out analyses on the absolute number of items recalled from the last position. There was a significant main effect of manner of reading the stimuli $[F(2,140)=26.69, M S \mathrm{e}=1.52]$. The crucial advantage of the mouthing condition over the silent condition was again significant $[F(1,70)=7.78$, $M S e=1.63]$. In this experiment, as in Experiment 1, mouthing led to enhanced recency in both absolute and relative terms. Additional comparisons of means showed that there were significant differences between the aloud and silent conditions $[F(1,70)=46.80, M S e=1.71]$ and between the mouthing and aloud conditions $[F(1,70)=$ $23.98, M S e=1.21$ ]. This latter comparison had been significant in Experiment 1 but did not reach significance in the analysis of our relative recency measure in either experiment. $^{2}$

Enhanced recency effects in the aloud and mouthing conditions are remarkable results, considering the fact that there was a retention interval containing a vocalized or mouthed distractor activity after every item (including the last). This result might be uninteresting if the distractor task was, for some reason, ineffective. However, there is reason to believe that this is not the case. Greene (1985) employed exactly the same distractor activity as was used here in the vocalized-distractor condition and demonstrated that $10 \mathrm{sec}$ of this activity was sufficient to completely eliminate the standard modality effect when this activity occurred only after the last item on the list. Since mouthed stimulation is almost as potent as auditory stimulation in eliminating auditory recency, and slightly more potent than auditory stimulation in eliminating mouthing recovery (Greene \& Crowder, 1984, Experiment 2), the mouthed version of this task should also have been effec- 
tive. Thus, the presence of enhanced recency effects in the aloud and mouthing conditions does not seem to be caused by any defects in the distractor activity used.

\section{GENERAL DISCUSSION}

These two experiments examined the effects of silent mouthing of list items in two paradigms using delayed recall. The two paradigms used were delayed serial recall with a silent distractor activity occurring during the retention interval and the continuous-distractor paradigm of free recall with a vocalized or mouthed distractor activity preceding and following each item on the list. The results of both experiments parallel those found earlier in immediate serial recall: Although mouthing leads to a decrement in memory for early items, there is an enhanced recency effect of the sort formerly believed to occur only with auditory stimulation. The results suggest that the mouthing recency effect occurs in the same range of situations as does the standard modality effect.

Taken together with Greene and Crowder's (1984, Experiment 1) finding that acoustic confusability decreases both auditory and mouthing recency, our results suggest that the mouthing effect and the standard modality effect have a common basis. This would mean that theories that attribute modality effects to a purely auditory sensory memory are incomplete at best (e.g., Crowder \& Morton, 1969; O. C. Watkins \& M. J. Watkins, 1980). Modality-like effects can be found in the absence of auditory stimulation.

Several other assumptions of the echoic-memory account of modality effects have been challenged by recent data. One of the properties commonly associated with a sensory memory store is brief duration. Although Crowder and Morton (1969) claimed that information in PAS persisted for at least a few seconds, they had no exact estimates for its duration. It now seems likely that the source of information responsible for the modality effect lasts for at least $20 \mathrm{sec}$ and possibly does not decay at all (M. J. Watkins \& Todres, 1980). This information is not simply an auditory analogue to the quickly decaying visual sensory store studied by Sperling (1960) and Averbach and Coriell (1961).

Another assumption of the echoic-memory account that has been challenged concerns the amount of information stored. Echoic memory was believed to hold one or two vowel sounds. Any subsequent auditory stimulation would interfere with the information held in echoic memory, with the amount of interference being a positive function of physical similarity. This sort of approach is completely unable to deal with the results found in the continuousdistractor paradigm, in which a robust auditory advantage occurred even when many seconds of auditory stimulation occurred after each item. One way to deal with this finding is to assume that the information responsible for the modality effect is held in a memory system with far greater capacity than the echoic-memory store proposed by Crowder and Morton (1969). ${ }^{3}$
It may be possible to revise the echoic-memory account to deal with these recent findings. We have discussed some tentative revisions elsewhere (Crowder, 1983; Greene \& Crowder, 1984), as has Frankish (1985; see also Frankish $\&$ Turner, 1984). However, it is clear that quite drastic revisions are needed in the echoic-memory account. Unlike the original proposal of Crowder and Morton (1969), the system responsible for the modality effect appears to persist for relatively long periods of time, to have an as yet undetermined (and possibly quite large) capacity, and to be not purely auditory at all.

A plethora of theories have been proposed as alternatives to an echoic-memory account and are capable of explaining some of the data that have been collected on the modality effect (see, e.g., D. E. Broadbent \& M. H. P. Broadbent, 1981; Campbell \& Dodd, 1980; Gardiner, 1983; Glenberg, 1984; Nairne \& McNabb, 1985; Penney, 1985; Shand \& Klima, 1981). However, none of these theories has attempted to explain the full range of data that was, at one time, accommodated by the echoicmemory theory of modality effects. For example, none of the theories listed above has tried to explain why the modality effect is found in recall of vowels but not in recall of stop consonants (Crowder, 1971). Moreover, the recent evidence that has challenged the echoic-memory account can be almost as troublesome for these alternative theories. Those theories that have been designed explicitly to explain why modality effects are found after prolonged auditory stimulation in the continuous-distractor paradigm (Gardiner, 1983; Glenberg, 1984) have no a priori basis on which to predict that mouthed and lipread items would also exhibit modality effects. Those theories that are capable of explaining the mouthing and lipreading data (D. E. Broadbent \& M. H. P. Broadbent, 1981; Campbell \& Dodd, 1980; Nairne \& McNabb, 1985; Shand \& Klima, 1981) do not predict that modality effects would be found in the continuous-distractor paradigm.

In short, there is currently no adequate unitary account for the modality effect. However, there is now considerable evidence that the echoic-memory account of Crowder and Morton (1969) is wrong in several fundamental ways. Additional experimentation will be necessary to decide whether the modality effect can best be explained by a revision of the original Crowder and Morton theory or by development of one of the many alternative accounts that have been proposed in recent years.

\section{REFERENCES}

Averbach, E., Coriell, A. S. (1961). Short-term memory in vision. Bell System Technical Journal, 40, 309-328.

BJORK, R.. A., \& WhITEN, W. B. (1974). Recency-sensitive retrieval processes in long-term free recall. Cognitive Psychology, 6, 173-189.

Brondbent, D. E., \& Brondbent, M. H. P. (1981). Recency effects in visual memory. Quanterly Joumal of Experimental Psychology, 33A, $1-15$.

Broadbent, D. E., Vines, R., Brondbent, M. H. P. (1978). Recency effects in memory as a function of modality of intervening events. Psychological Research, 40, 5-13. 
CAMPBell, R., \& DodD, B. (1980). Hearing by eye. Quarterly Journal of Experimental Psychology, 32, 85-99.

ColthearT, M. (1984). Sensory memory: A tutorial review. In H. Bouma \& D. G. Bouwhuis (Eds.), Attention and performance X: Control of language processes. Hillsdale, NJ: Erlbaum.

Conrad, R., \& Hull, A. J. (1968). Input modality and the serial position curve in short-term memory. Psychonomic Science, 10, 135-136.

Corballis, M. C. (1966). Rehearsal and decay in immediate recall of visually and aurally presented items. Canadian Journal of Psychology, 20, 43-51.

Craik, F. I. M. (1969). Modality effects in short-term memory. Journal of Verbal Learning \& Verbal Behavior, 8, 658-664.

Crowder, R. G. (1967). Prefix effects in immediate memory. Canadian Journal of Psychology, 21, 450-461.

CrowDER, R. G. (1970). The role of one's own voice in immediate memory. Cognitive Psychology, 1, 157-178.

CRowDER, R. G. (1971). The sounds of vowels and consonants in immediate memory. Journal of Verbal Leaming \& Verbal Behavior, 10 , 587-596.

Crowder, R. G. (1983). The purity of auditory memory. Philosophical Transactions of the Royal Society, B, 302, 251-265.

Crowder, R. G., \& MorTon, J. (1969). Precategorical acoustic storage (PAS). Perception \& Psychophysics, 5, 365-373.

DALLETT, K. M. (1965). "Primary memory": The effects of redundancy upon digit repetition. Psychonomic Science, 3, 237-238.

ENGLE, R. W., \& RobERTs, J. S. (1982). How long does the modality effect persist? Bulletin of the Psychonomic Society, 19, 343-346.

FrankISH, C. (1985). Modality-specific grouping effects in short-term memory. Journal of Memory \& Language, 24, 200-209.

Frankish, C., \& TURNer, J. (1984). Delayed suffix effects at very short delays. Journal of Experimental Psychology: Learning, Memory, \& Cognition, 10, 767-777.

GARDINER, J. M. (1983). On recency and echoic memory. Philosophical Transactions of the Royal Society of London, B, 302, 267-282.

Gardiner, J. M., \& GregG, V. H. (1979). When auditory memory is not overwritten. Journal of Verbal Learning \& Verbal Behavior, 18, 705-719.

Gathercole, S. E., GregG, V. H., \& Gardiner, J. M. (1983). Influences of delayed distraction on the modality effect in free recall. British Journal of Psychology, 74, 223-232.

Glenderg, A. M. (1984). A retrieval account of the long-term modality account. Journal of Experimental Psychology: Learning, Memory, \& Cognition, 9, 231-255.

GREENBERG, S. N., \& ENGLE, R. W. (1983). Voice change in the stimulus suffix effect: Are the effects structural or strategic? Memory \& Cognition, 11, 551-556.

GrEenE, R. L. (1985). Constraints on the long-term modality effect. Joumal of Memory \& Language, 24, 526-541.

Greene, R. L., \& Crowder, R. G. (1984). Modality and suffix effects in the absence of auditory stimulation. Joumal of Verbal Learning \& Verbal Behavior, 23, 371-382.

MURDOCK, B. B., JR., \& WALKER, K. D. (1969). Modality effects in free recall. Journal of Verbal Learning \& Verbal Behavior, 8, 665-676.

MURRAY, D. J. (1966). Vocalization-at-presentation and immediate recall, with varying recall methods. Quarterly Journal of Experimental Psychology, 18, 9-18.

NAIRNE, J. S., \& MCNABB, W. L. (1985). More modality effects in the absence of sound. Journal of Experimental Psychology: Learning, Memory, \& Cognition, 11, 596-604.

NaIRNE, J. S., \& WALTERS, V. L. (1983). Silent mouthing procedures modality- and suffix-like effects. Journal of Verbal Learning \& Verbal Behavior, 22, 475-483.

Penney, C. G. (1985). Elimination of the suffix effect on preterminal list items with unpredictable list length: Evidence for a dual model of suffix effects. Journal of Experimental Psychology: Learning, Memory, \& Cognition, 11, 229-247.

Routh, D. A., \& MAYes, J. T. (1974). A robust recency effect in delayed (ordered) recall. IRCS Medical Science: Psychology, 2, 1618.

Shand, M. A., \& Klima, E. S. (1981). Nonauditory suffix effects in congenitally deaf signers of American Sign Language. Journal of Experimental Psychology: Human Learning \& Memory, 7, 464-474.

SPERLING, G. (1960). The information available in brief visual presentations, Psychological Monographs, 74(Whole No. 11).

SPOEHR, K. T., \& CoRIN, W. J. (1978). The stimulus suffix effect as a memory coding phenomenon. Memory \& Cognition, 6, 583-589.

W AtKins, M. J., \& TODRES, A. K. (1980). Suffix effects manifest and concealed: Further evidence for a 20 -second echo. Journal of Verbal Learning \& Verbal Behavior, 19, 46-53.

Watkins, M. J., Watkins, O. C., Craik, F. I. M., \& Mazuryk, G. (1973). Effects of nonverbal distraction on short-term storage. Journal of Experimental Psychology, 101, 296-300.

Watkins, O. C., \& WatKINS, M. J. (1980). The modality effect and echoic persistence. Joumal of Experimental Psychology: General, 109, 251-278

W ATKINS, O. C., \& WATKINS, M. J. (1982). Lateral inhibition and echoic memory: Some comments on Crowder's (1978) theory. Memory \& Cognition, 10, 279-286.

\section{NOTES}

1. The analyses reported thus far have all used subjects as the random factor. We repeated the analyses on absolute recall of terminal items using lists, rather than subjects, as a random factor. The main effect of condition was significant using either the item criterion $[F(2,78)=$ $113.53, M S e=2.18]$ or the position criterion $[F(2,78)=102.85, M S e$ $=2.22]$. The crucial comparison between the mouthing and silent conditions was easily significant $[F(1,39)=54.82, M S e=2.28$, using the item criterion, and $F(1,39)=34.63, M S e=2.14$, using the position criterion]. The aloud condition led to significantly greater terminal-item recall than the mouthing condition using either the item criterion $[F(1,39)$ $=58.34, M S e=2.10]$ or the position criterion $[F(1,39)=72.55, M S e$ $=2.20$ ]. The aloud condition led to significantly greater recency than the silent condition using either the item criterion $[F(1,39)=228.12$. $M S e=2.17]$ or the position criterion $[F(1,39)=193.67, M S \mathrm{e}=2.33]$. In short, exactly the same conclusions are reached using either subjects or lists as a random factor.

2. The analyses on absolute recall of terminal items in Experiment 2 were repeated using lists, rather than subjects, as random factor. There was again a main effect of condition $[F(2,38)=6.84, M S e=1.33]$. The mouthing condition led to significantly greater recall of terminal items than did the silent condition $[F(1,19)=4.82, M S e=2.01]$. In addition, there were significant differences between the aloud and mouthing conditions $[F(1,19)=4.79, M S e=1.82]$ and between the aloud and silent conditions $[F(1,19)=5.06, M S e=1.42]$.

3. It may be possible to explain modality effects in the continuousdistractor paradigm without abandoning the assumption that modality effects reflect the operation of some sort of limited-capacity store. For example, one could propose that access to this store is not automatic and that distractor stimulation does not enter such a store when it occurs after every item. In other words, this store could be selective. However, since the modality effect in the continuous-distractor paradigm is dependent on the semantic relationship of the list items to the distractor stimulation (Greene, 1985), such an account still would involve radical changes from the original echoic-memory theory.

(Manuscript received May 30, 1985; revision accepted for publication January $21,1986$. ) 